\title{
Rebeca Monroy Nasr, Gabriela Pulido Llano, José Mariano Leyva (coords.), Nota roja. Lo anormal y lo criminal en la historia de México, México, Instituto Nacional de Antropología e Historia, 2018, p. 422
}

Copyright: (c) 2020. Castrillón, C. Este es un artículo de acceso abierto, distribuido bajo los términos de la licencia https://creativecommons.org/licenses/by-nc$\mathrm{sa} / 4.0 /$ la cual permite el uso sin restricciones, distribución y reproducción en cualquier medio, siempre y cuando que el original, el autor y la fuente sean acreditados.

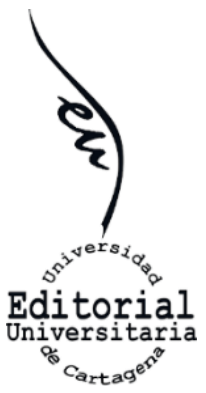

Las investigaciones sobre lo criminal, lo anormal y lo transgresor desde una revisión histórica en América Latina y el Caribe han tomado bastante fuerza desde, hace ya, algunos años. En algunos países es amplio el desarrollo de obras que utilizan la prensa escrita y revistas especializadas en criminalidad, como fuente histórica, para entender los discursos y las representaciones que exponen experiencias de las que se derivan conductas entendidas como criminales en determinados momentos históricos. El conjunto de estudios realizó una lectura de los procesos creativos y narrativos del periódico para sentar unas bases analíticas para dar apertura a una historia sociocultural del crimen y la transgresión que incluye el análisis, por un lado, de experiencias en el mundo urbano: vicios, prostitución, bares, vida nocturna, delito, etc. Y por otro, la vida íntima: conflictos familiares, homicidios, infanticidios, aborto, entre otros.

La obra cuya coordinación se encuentra a cargo de Rebeca Monroy Nasr, Gabriela Pulido Llano y José Mariano Leyva reúne un conjunto de trabajos realizado por considerables investigadores e investigadoras quienes han aportado desde diferentes perspectivas a la historia de la nota roja mexicana. También, incluyeron ejes de análisis cuantitativos, cualitativos y establecieron diálogos interdisciplinares (derecho, antropología, psicología, periodismo, historia del arte, criminología y literatura). El conjunto de obras asumió el complejo reto de revisar inquietudes, métodos, conceptualizaciones y aproximaciones al análisis periodístico para brindar claves y entender las formas en que se ha usado la noticia "como empoderamiento de un grupo para mostrar: el castigo, a otros infringir, miedo en la población y determinar ciertas conductas" (p. 26). De manera que, veremos en las propuestas una articulación entre diversos circuitos culturales (cine, literatura, fotografía), que se nutren y nutren a otros discursos participando en la construcción de representaciones relacionadas con el crimen.

El libro, de lectura atrayente, se apoya de un conjunto seleccionado de fuentes, el cual contribuye al nuevo auge de la historia cultural. A pesar de todo, el objeto de estudio (nota roja) propuesto por la publicación tiene muy poco tiempo de desarrollo al no ser considerado como legítimo hace algunos años. De esta manera, la fuente periodística "arroja información sobre los individuos, las sociedades, cuestiones morales, éticas, políticas, estéticas algunos acercamientos que permiten estudiar considerados marginales" (p. 36). Sin embargo, es muy significativo el sentido crítico con el que abordan las fuentes dando apertura a extenderse nuevas formas de releer y ver los documentos ya conocidos. La temporalidad abarcada en el texto va desde finales del siglo XIX al XXI, épocas en la que se dan diferentes transferencias de ideas, discursos e imágenes que termina en instituciones como los medios. 
Con todo, Nota roja. Lo anormal y lo criminal en la historia de México se encuentra fraccionado en un prologó, agradecimientos, introducción y quince artículos. Se pueden resaltar las investigaciones y algunos los tópicos tratados de Julia Tuñón (Notas para problematizar), Nadia Mendez Di Pardo (Alcoholismo, enfermedad), José Mariano Leyva (Asesinatos), German Álvarez Díaz de León (Magnicida), Saydi Nuñez Cetina (Crimen pasional), María Eugenia Sánchez Calleja (Niño delincuente), Richardo Pérez Montfort (Drogas), Esteban Terán Rodríguez (Suicidio), Rebeca Monroy Nasr (Revista Todo), Gabriela Pulido Llano (Magazine de Policía), Fabiola Bailón Vásquez (Trata de blancas y prostitución), María Eugenia del Valle Prieto (Muerte), Beatriz Argelia González García (Muerte), María del Carmen Montenegro Nuñez (Asesinato), Luis Hernández Navarro (Nota roja), cada ensayo y cada lectura periodistica promueven y aportan de gran manera el impulso de la historia cultural, el crimen y la transgresión.

Los trabajos señalados, muestran el periodismo como un medio en el que se transmitieron contenidos que nos acercan a experiencias de la vida cotidiana transfiguradas en una criminalización o transgresión dentro de una sociedad. Nos acerca a unos cambios y permanencias en la mentalidad de las personas y los códigos que regulan determinados comportamientos. Así, las denuncias de prensa son expuestas como una fuente escenográfica sobre actuaciones destacadas por su forma de accionar. Describen escenarios públicos que se vuelven plataformas de conflicto y rivalidad, pero también exhibe paredes, de lugares privados, que escuchan y dicen. En otras palabras, se analizan las redes de comunicación, los medios empleados, las estrategias utilizadas, los lugares, las personas, además de la transmisión oral y escrita.

Interesa destacar del libro, la utilización de la nota roja como lugar de enunciaciones o escritos de información, lo que a su vez construyó o formó estereotipos, emociones, y reglas entorno a determinadas personas que excedieron los límites de lo permitido. El conjunto de investigaciones permite a futuras generaciones explorar desde diferentes marcos teóricos y conceptuales causas y consecuencias de la criminalidad y la transgresión. Es importante resaltar que, los contenidos abordados fueron estudiados desde diferentes ángulos lo que abre a una lectura más atenta para la apertura y exploración de otras fuentes.

Por último, interesa invitar al estudio de la nota roja como un género literario empleado en los periódicos, el comic, la fotografía como otras maneras de ver los medios al que fue expuesta la representación criminal. La prensa es una magnifica fuente para explorar formas de comunicación como el traspaso de lo oral a lo escrito que pasa ser convertido en una amplia difusión.

Carlos Mario Castrillón Castro

Estudiante del Doctorado en Estudios Críticos de Género Universidad Iberoamericana, Ciudad de México 